Correspondence

Peter Kämpfer

peter.kaempfer@umwelt.

uni-giessen.de

P. D. Rekha

rekhapd@hotmail.com

\section{Fontibacter flavus gen. nov., sp. nov., a member of the family 'Cyclobacteriaceae', isolated from a hot spring}

Peter Kämpfer, ${ }^{1}$ Chiu-Chung Young, ${ }^{2}$ Wen-Ming Chen, ${ }^{3}$ P. D. Rekha, ${ }^{4}$ Kerstin Fallschissel, ${ }^{1}$ Nicole Lodders, ${ }^{1}$ Jui-Hsing Chou, ${ }^{2}$ Fo-Ting Shen, ${ }^{2}$ Alexa Frischmann, ${ }^{5}$ Hans-Jürgen Busse ${ }^{5}$ and A. B. Arun ${ }^{4}$

\author{
${ }^{1}$ Institut für Angewandte Mikrobiologie, Justus-Liebig Universität Giessen, IFZ - Heinrich-Buff-Ring \\ 26-32, D35392 Giessen, Germany \\ ${ }^{2}$ Department of Soil Environmental Science, College of Agriculture and Natural Resources, \\ National Chung Hsing University, Taichung, Taiwan, ROC \\ ${ }^{3}$ Laboratory of Microbiology, Department of Seafood Science, National Kaohsiung Marine \\ University, No. 142, Hai-Chuan Rd, Nan-Tzu, Kaohsiung City 811, Taiwan, ROC \\ ${ }^{4}$ Yenepoya Research Center, Yenepoya University, Nityanada Nagar, Deralakatte, \\ Mangalore 575 018, Karnataka, India \\ ${ }^{5}$ Institut für Bakteriologie, Mykologie und Hygiene, Veterinärmedizinische Universität Wien, Wien, \\ Austria
}

The taxonomic position of a bright orange-pigmented bacterial strain, designated CC-GZM-130 ${ }^{\top}$, isolated from a water sample of the Guan-zing-ling hot spring, southern Taiwan, was studied. The strain was able to grow on nutrient agar at $25-40{ }^{\circ} \mathrm{C}$ and in the presence of $1-3 \%(\mathrm{w} / \mathrm{v}) \mathrm{NaCl}$. Comparative analyses of the $16 \mathrm{~S}$ rRNA gene sequence showed that the isolate was grouped in the vicinity of the genus Aquiflexum with the highest sequence similarity of $92.1 \%$ to the type strain of Aquiflexum balticum, followed by sequence similarities of $92.0,91.6$ and $91.5 \%$ to the type strains of Algoriphagus ornithinivorans, Algoriphagus hitonicola and Belliella baltica, respectively. The polyamine pattern showed that the major compound was sym-homospermidine. The quinone system was menaquinone MK-7. The polar lipid profile was composed predominantly of phosphatidylethanolamine, three polar lipids and one aminolipid. Minor amounts of other lipids were also detectable. The main characteristics of the fatty acid profiles of strain CC-GZM-130 ${ }^{\top}, B$. baltica and Aquiflexum balticum were similar, with iso- $\mathrm{C}_{15: 0}$, iso- $\mathrm{C}_{17: 1} \omega 9 \mathrm{c}$ and iso- $\mathrm{C}_{17: 0} 3-\mathrm{OH}$ as the major fatty acids, but some qualitative and quantitative differences were observed. The DNA $\mathrm{G}+\mathrm{C}$ content of the novel strain was $53.2 \mathrm{~mol} \%$. The isolate clearly differed genotypically and phenotypically from representatives of the most closely related genera. On the basis of these differences, a novel species in a new genus, Fontibacter flavus gen. nov., sp. nov., is proposed with CC-GZM-130 ${ }^{\top}\left(=\right.$ CCUG $57694^{\top}=$ CCM $\left.7650^{\top}\right)$ as the type strain of the type species.
The genera Aquiflexum and Belliella, proposed by Brettar et al. (2004a, b), respectively, contain the single species Aquiflexum balticum and Belliella baltica, which were both isolated from the Baltic Sea. Both genera were described

Abbreviations: NA, nitroanilide; NP, nitrophenyl; PE, phosphatidylethanolamine.

The GenBank/EMBL/DDBJ accession number for the 16S rRNA gene sequence of strain CC-GZM-130 ${ }^{\top}$ is FN421478.

Details of the composition of Guan-zing-ling hot spring water samples (Table S1), additional chemotaxonomic data (Table S2) and a neighbourjoining tree based on 16S rRNA gene sequences (Fig. S1) are available with the online version of this paper. as comprising Gram-negative, rod-shaped, oxidase- and catalase-positive bacteria with a heterotrophic and aerobic metabolism. The predominant fatty acids for both genera were iso- $\mathrm{C}_{15: 0}$, anteiso- $\mathrm{C}_{15: 0}$, iso- $\mathrm{C}_{15: 1} \mathrm{G}$ and iso- $\mathrm{C}_{16: 1} \mathrm{H}$. The genera Aquiflexum and Belliella belong to the family 'Cyclobacteriaceae' of the phylum 'Bacteroidetes' (Ludwig et al., 2008).

An orange-pigmented strain, designated CC-GZM- $130^{\mathrm{T}}$, was isolated on nutrient agar (Oxoid) from a water sample of the Guan-zing-ling hot spring located in southern Taiwan. The temperature of the spring water ranged from 45 to $65{ }^{\circ} \mathrm{C}$ and the $\mathrm{pH}$ was 8 . The chemical composition 
of the Guan-zing-ling hot spring water sample is given in Supplementary Table S1 (available in IJSEM Online). Strain CC-GZM- $130^{\mathrm{T}}$ was maintained and subcultivated on nutrient agar at $28{ }^{\circ} \mathrm{C}$ for $48 \mathrm{~h}$ for analysis of its $16 \mathrm{~S}$ rRNA gene sequence and chemotaxonomic, biochemical and growth characteristics. Growth was also tested on tryptic soy agar and MacConkey agar (both Oxoid). The $\mathrm{pH}$ range for growth was determined in nutrient broth (Difco) which was adjusted prior to sterilization to various $\mathrm{pH}$ values ( $\mathrm{pH} 3-11$ at intervals of $1.0 \mathrm{pH}$ units) using appropriate biological buffers (Chung et al., 1995). Growth at various temperatures $(4,10,15,20,25,30,37,40$ and $50{ }^{\circ} \mathrm{C}$ ) and in the presence of different $\mathrm{NaCl}$ concentrations $(1-12 \%$ at intervals of $1.0 \%)$ was measured in nutrient broth. The Gram reaction was tested by the modified method of Gerhardt et al. (1994) and motility was tested by light microscopy of cells grown for 3 days in nutrient broth (Oxoid) at $30{ }^{\circ} \mathrm{C}$. Accumulation of poly- $\beta$ hydroxybutyrate granules was assessed by light microscopy after staining of cells with Sudan Black.

Oxidase activity was tested using the bioMérieux oxidase reagent according to the instructions of the manufacturer. Physiological characterization and additional biochemical tests were performed to assess the carbon source utilization pattern; hydrolysis of 19 substrates was investigated as described by Kämpfer et al. (1991). The 16S rRNA gene was analysed as described by Kämpfer et al. (2003). Phylogenetic trees and nucleotide sequence similarities were calculated using the ARB software package (Strunk et al., 2000; Ludwig et al., 2004) and the corresponding SILVA SSURef 95 database (version July 2008; Pruesse et al., 2007). The sequenced length of the 16S rRNA gene of strain CC-GZM- $130^{\mathrm{T}}$ was $1387 \mathrm{bp}$. A phylogenetic tree reconstructed using the maximum-likelihood method with
fastDNAml (Olsen et al., 1994) is shown in Fig. 1. The type strain of Sporocytophaga myxococcoides was used as an outgroup. Tree reconstruction using the neighbour-joining method showed similar clustering of strain CC-GZM-130 ${ }^{\mathrm{T}}$ and its nearest relatives, but the species of the genus Algoriphagus clustered together (see Supplementary Fig. S1 in IJSEM Online). The bootstrap values shown are based on 1000 replications. According to distance calculations, the most closely related strains were the type strains of Aquiflexum balticum and Algoriphagus ornithinivorans showing $92.1 \%$ and $92.0 \%$ sequence similarities, respectively, followed by Algoriphagus hitonicola (91.6\% sequence similarity) and B. baltica (91.5\% sequence similarity). Because of these low similarities, DNA-DNA hybridization experiments were not performed.

Chemotaxonomic analyses were performed on strain CCGZM- $130^{\mathrm{T}}$ as well as on the reference strains Aquiflexum balticum DSM $16537^{\mathrm{T}}$ and B. baltica DSM $15883^{\mathrm{T}}$, grown under the same conditions. Isoprenoid quinones were extracted and separated as described previously by Minnikin et al. (1984) and analysed by HPLC as described by Collins (1985). For analyses of polyamines and polar lipids, cells were grown in marine broth (Becton Dickinson 2216) at $28{ }^{\circ} \mathrm{C}$. Polyamines were extracted according to Busse \& Auling (1988) from biomass that had been harvested at approximately $70 \%$ of the maximum optical density. HPLC analysis of polyamines was carried out using the instrumentation described by Stolz et al. (2007). Strain CC-GZM-130 ${ }^{\mathrm{T}}$, Aquiflexum balticum DSM $16537^{\mathrm{T}}$ and $B$. baltica DSM $15883^{\mathrm{T}}$ exhibited highly similar polyamine patterns with sym-homospermidine as the single major compound and low levels of other polyamines. The polyamine pattern of strain CC-GZM- $130^{\mathrm{T}}$ comprised $17.7 \mu \mathrm{mol}$ sym-homospermidine $(\mathrm{g} \text { dry weight })^{-1}, 1.2 \mu \mathrm{mol}$

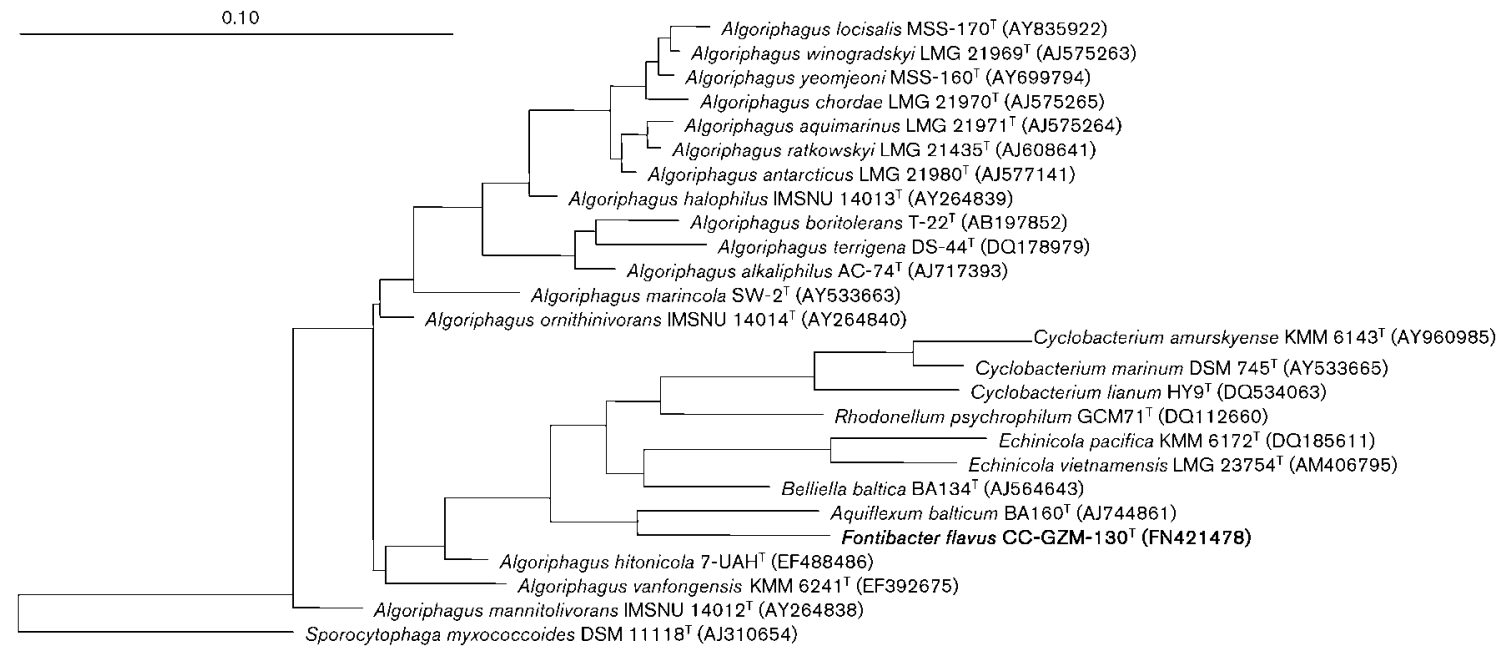

Fig. 1. Phylogenetic tree based on $16 \mathrm{~S}$ rRNA gene sequences showing the relationship between strain $C C-G Z M-130^{\top}$ and representative members of related species. The tree was constructed with the maximum-likelihood method. Bar, 0.10 nucleotide substitutions per nucleotide position. 
spermidine (g dry weight) ${ }^{-1}$ and trace amounts $[<0.2 \mu \mathrm{mol}$ ( $g$ dry weight $)^{-1}$ ] of putrescine, cadaverine and spermine. The polyamine pattern of Aquiflexum balticum DSM $16537^{\mathrm{T}}$ comprised $16.5 \mu \mathrm{mol}$ sym-homospermidine (g dry weight $)^{-1}, 0.2 \mu \mathrm{mol}$ spermidine $(\mathrm{g} \text { dry weight })^{-1}$ and traces of putrescine, cadaverine and spermine, whereas that of $B$. baltica DSM $15883^{\mathrm{T}}$ comprised $22.0 \mu \mathrm{mol}$ sym-homospermidine (g dry weight) ${ }^{-1}, 0.3 \mu \mathrm{mol}$ spermidine (g dry weight $)^{-1}$ and trace amounts of putrescine, cadaverine and spermine. Hence, polyamine patterns were not useful for discrimination between the three strains.

Polar lipids were extracted and analysed as described previously (Tindall, 1990a, b; Altenburger et al., 1996). In the polar lipid profiles, strain CC-GZM-130 ${ }^{\mathrm{T}}$, Aquiflexum balticum DSM $16537^{\mathrm{T}}$ and B. baltica DSM $15883^{\mathrm{T}}$ shared some major polar lipids, but differences in the profiles enabled the three strains to be distinguished from each other (see Supplementary Table S2 in IJSEM Online). Major polar lipid components of strain CC-GZM- $130^{\mathrm{T}}$ (Fig. 2a) were phosphatidylethanolamine (PE) and an unknown polar lipid L2 detectable with molybdatophosphoric acid but not with any of the other specific reagents employed, such as molybdenum blue, ninhydrin reagent or $\alpha$-naphthol reagent. Furthermore, moderate amounts of an unknown aminolipid (AL1) and five unknown polar lipids (L1, L3, L4, L5, L6), and minor to trace amounts of one unknown phospholipid (PL1) and two polar lipids (L7, L8), were detected. The polar lipid profile of Aquiflexum balticum DSM $16537^{\mathrm{T}}$ (Fig. 2b) revealed PE and unknown polar lipids L2 and L6 as major lipids, moderate amounts of unknown lipids L8 and L10 and an unknown phospholipid (PL2), and minor amounts of unknown aminolipid AL1 and polar lipid L11. The polar lipid profile of B. baltica DSM $15883^{\mathrm{T}}$ (Fig. 2c) revealed PE and unknown lipids L2 and L6 as major lipids, moderate amounts of unknown lipids L4, L5 and L8, and minor amounts of unknown lipids L1, L7, L9, L12 and PL2. Lipid L12 exhibited chromatographic behaviour that was similar to PL1 of strain CC-GZM-130 ${ }^{\mathrm{T}}$, but unambiguous staining for phosphate using molybdenum blue was not observed, which might be related to the very small concentration of this lipid in B. baltica. Although the three strains shared several characteristics, some interesting differences were observed. Strain CC-GZM- $130^{\mathrm{T}}$ could be distinguished from Aquiflexum balticum DSM $16537^{\mathrm{T}}$ based on the presence of lipids L1, L3, L4 and PL1 in its polar lipid profile and the absence of L10, L11 and PL2 (Supplementary Table S2 in IJSEM Online). The polar lipid profile of strain CC-GZM- $130^{\mathrm{T}}$ shared more traits with that of B. baltica DSM $15883^{\mathrm{T}}$, but could be distinguished from it based on the absence of L3 and AL1 in B. baltica DSM $15883^{\mathrm{T}}$ and the absence of L9 and PL2 in CC-GZM$130^{\mathrm{T}}$. So far, within the genus Algoriphagus, only the polar lipids of Algoriphagus olei (Young et al., 2009) have been determined. This species also shows the presence of PE, L6 (designated L1 in Young et al., 2009) and PL1, but the presence of an unidentified aminophospholipid and an
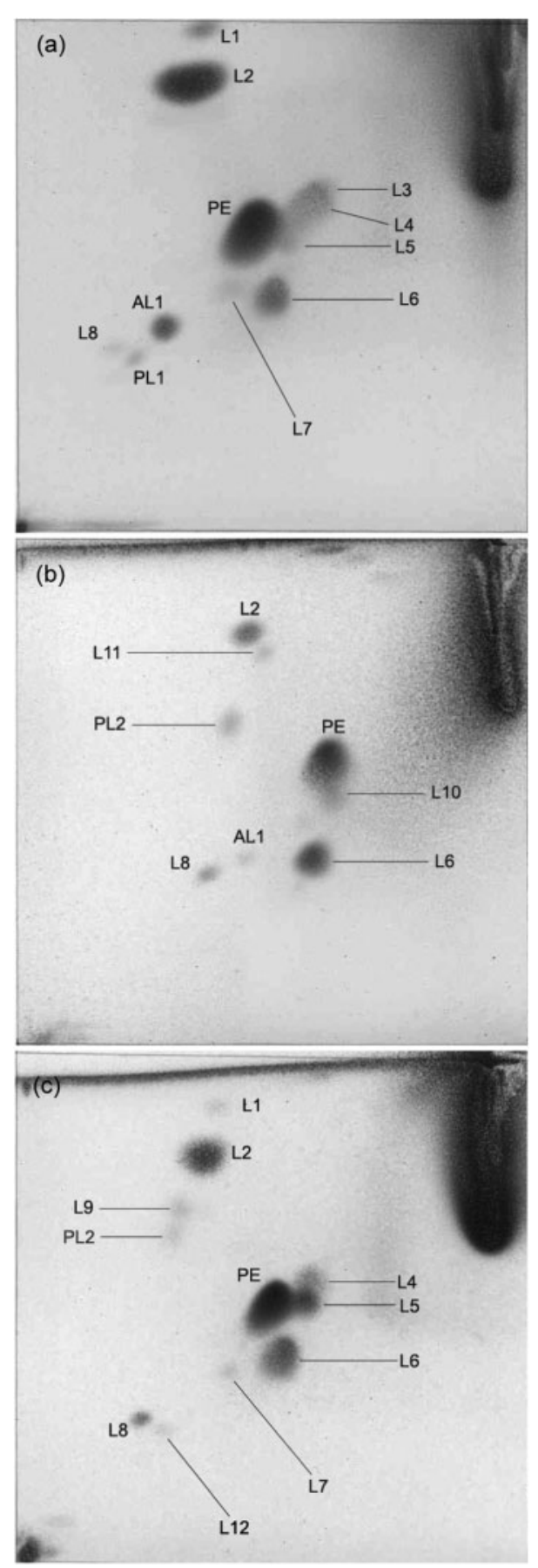

Fig. 2. Polar lipid profile of strain CC-GZM-130 ${ }^{\top}$ (a), A. balticum DSM $16537^{\top}$ (b) and B. baltica DSM $15883^{\top}$ (c) after twodimensional TLC and detection with molybdatophosphoric acid. PE, phosphatidylethanolamine; PL1/PL2, unknown phospholipids; AL1, unknown aminolipid; L1-11, unknown polar lipids which were only detected using molybdatophosphoric acid. First dimension, left to right; second dimension, bottom to top.

aminolipid distinguishes it from the three strains examined in this study. However, these characteristics may reflect the distant relatedness between the three strains and 
Algoriphagus olei, indicated by low $16 \mathrm{~S}$ rRNA gene sequence similarities $(<92.5 \%)$, and appear to be useful for genus differentiation. The cellular fatty acid composition of strain CC-GZM- $130^{\mathrm{T}}$ was determined as described by Kämpfer \& Kroppenstedt (1996). The most abundant fatty acid was iso- $\mathrm{C}_{15: 0}$, followed by iso- $\mathrm{C}_{17: 1} \omega 9 c$ and iso$\mathrm{C}_{17: 0} 3-\mathrm{OH}$. The complete fatty acid pattern of strain CCGZM- $130^{\mathrm{T}}$ is shown in Table 1 along with those of the type strains of Aquiflexum balticum and B. baltica. The three fatty acid profiles were similar, but clear differences could also be observed. Clear physiological/biochemical differences were also observed in a comparative analysis between strain CC-GZM- $130^{\mathrm{T}}$ and the type strains of Aquiflexum balticum and B. baltica. Details are given in Table 2.

On the basis of these results, strain CC-GZM- $130^{\mathrm{T}}$ is described as a representative of a novel species in a new

Table 1. Fatty acid compositions of strain CC-GZM-130 ${ }^{\top}$ and the type strains of related species

Strains: 1, CC-GZM- $130^{\mathrm{T}}$; 2, Aquiflexum balticum DSM $16537^{\mathrm{T}}$ (data in parentheses from Brettar et al., 2004b); 3, Belliella baltica DSM $15883^{\mathrm{T}}$ (data in parentheses from Brettar et al., 2004a). All data, except those given in parentheses, are from this study (strains were grown on tryptone soy agar at $28{ }^{\circ} \mathrm{C}$ for $72 \mathrm{~h}$ prior to extraction). Results are presented as percentages of the total fatty acids; only those fatty acids amounting to $>1 \%$ of the total fatty acids in all strains are shown. Fatty acids representing $>5 \%$ of the total fatty acids are in bold. ND, Not detected; tr, traces $(<1 \%)$.

\begin{tabular}{|c|c|c|c|}
\hline Fatty acid & 1 & 2 & 3 \\
\hline iso- $\mathrm{C}_{14: 0}$ & ND & $2.0(4.8)$ & $\mathrm{ND}(2.0)$ \\
\hline $\mathrm{C}_{15: 0}$ & ND & ND & $1.1(2.9)$ \\
\hline iso- $\mathrm{C}_{15: 0}$ & 33.5 & $11.2(22.6)$ & $27.5(20.7)$ \\
\hline anteiso- $\mathrm{C}_{15: 0}$ & 3.1 & $16.5(18.5)$ & $6.9(4.5)$ \\
\hline iso- $\mathrm{C}_{15: 0} 3-\mathrm{OH}$ & 3.5 & $4.3(1.6)$ & $3.5(2.2)$ \\
\hline $\mathrm{C}_{15: 0} 2-\mathrm{OH}$ & 2.0 & $2.3(\mathrm{ND})$ & $\operatorname{tr}(\mathrm{ND})$ \\
\hline iso- $\mathrm{C}_{15: 1} \mathrm{G}$ & 8.0 & $5.6(9.4)$ & $11.0(10.2)$ \\
\hline $\mathrm{C}_{15: 1} \omega 6 c$ & $\mathrm{ND}$ & $1.0(\mathrm{ND})$ & $\operatorname{tr}(2.1)$ \\
\hline iso- $\mathrm{C}_{16: 0}$ & $\mathrm{ND}$ & $4.7(4.2)$ & $\operatorname{tr}(2.6)$ \\
\hline $\mathrm{C}_{16: 0} 3-\mathrm{OH}$ & ND & $1.5(\mathrm{ND})$ & $\operatorname{tr}(<1.1)$ \\
\hline $\mathrm{C}_{16: 0}$ & 1.3 & ND & ND \\
\hline iso- $\mathrm{C}_{16: 1} \mathrm{H}$ & ND & $11.1(9.4)$ & $\operatorname{tr}(3.5)$ \\
\hline iso- $\mathrm{C}_{16: 0} 3-\mathrm{OH}$ & $\operatorname{tr}$ & $4.1(2.0)$ & $\operatorname{tr}(1.9)$ \\
\hline $\mathrm{C}_{16: 1} \omega 5 c$ & 1.4 & $1.98(2.0)$ & $2.3(3.3)$ \\
\hline Summed feature ${ }^{*}$ & 4.5 & $8.7(6.1)$ & $9.5(9.3)$ \\
\hline iso- $\mathrm{C}_{17: 0} 3-\mathrm{OH}$ & 9.9 & $5.3(1.4)$ & $10.9(3.2)$ \\
\hline $\mathrm{C}_{17: 0} 2-\mathrm{OH}$ & $\operatorname{tr}$ & $3.3(\mathrm{ND})$ & $1.3(\mathrm{ND})$ \\
\hline anteiso- $\mathrm{C}_{17: 1} \mathrm{~B}$ & 8.6 & $5.9(2.5)$ & $7.7(3.7)$ \\
\hline $\mathrm{C}_{17: 1} \omega 6 c$ & ND & $5.3(3.0)$ & $1.8(7.3)$ \\
\hline $\mathrm{C}_{17: 1} \omega 8 c$ & $\mathrm{ND}$ & ND & $1.19(1.2)$ \\
\hline iso- $\mathrm{C}_{17: 1} \omega 9 c$ & 15.6 & $5.3(5.2)$ & $9.8(8.4)$ \\
\hline anteiso- $\mathrm{C}_{17: 1} \omega 9 c$ & ND & $1.1(1.1)$ & ND \\
\hline iso- $\mathrm{C}_{19: 1} \mathrm{I}$ & ND & $1.5(1.5)$ & $\operatorname{tr}(\mathrm{ND})$ \\
\hline Not identified & 8.4 & $1.1(4.6)$ & $2.0(7.7)$ \\
\hline
\end{tabular}

${ }^{*}$ Summed feature comprises $\mathrm{C}_{16: 1} \omega 7 c /$ iso- $\mathrm{C}_{15: 0} 2-\mathrm{OH}$. genus for which the name Fontibacter flavus gen. nov., sp. nov. is proposed.

\section{Description of Fontibacter gen. nov.}

Fontibacter (Fon.ti.bac'ter. L. n. fons fontis a spring; N.L. masc. n. bacter a rod; N.L. masc. n. Fontibacter a rod isolated from a spring sample).

Cells are Gram-reaction-negative, non-motile, non-sporeforming rods. Aerobic and oxidase-positive. symHomospermidine is the major polyamine. The major quinone system is menaquinone MK-7. The polar lipid profile is composed predominantly of PE, three polar lipids and one aminolipid. The major cellular fatty acids are iso- $\mathrm{C}_{15: 0}$, iso- $\mathrm{C}_{17: 1} \omega 9 \mathrm{c}$ and iso- $\mathrm{C}_{17: 0} 3-\mathrm{OH}$. The

Table 2. Differential biochemical characteristics of strain CC-GZM-130 ${ }^{\top}$ and related type strains

Strains: 1, CC-GZM-130 ${ }^{\mathrm{T}}$; 2, Aquiflexum balticum DSM $16537^{\mathrm{T}} ; 3, \mathrm{~B}$. baltica DSM $15883^{\mathrm{T}}$. All data are from this study. All strains were positive for hydrolysis of $o \mathrm{NP}-\beta$-D-galactopyranoside, $p \mathrm{NP}-\alpha$-Dglucopyranoside, $\quad p \mathrm{NP}-\beta$-D-glucopyranoside, bis- $p \mathrm{NP}$-phosphate, $p \mathrm{NP}$-phosphoryl-choline and L-glutamate- $\gamma$-3-carboxy- $p \mathrm{NA}$ and for utilization of cellobiose, D-fructose, D-galactose, D-glucose, Dmannose, sucrose and trehalose. All strains were negative for utilization of $\mathrm{N}$-acetylgalactosamine, gluconate, D-ribose, D-adonitol, D-mannitol, acetate, propionate, cis-aconitate, trans-aconitate, adipate, 4-aminobutyrate, azelate, citrate, fumarate, glutarate, DL-3hydroxybutyrate, itaconate, DL-lactate, L-malate, mesaconate, oxoglutarate, pyruvate, suberate, L-alanine, $\beta$-alanine, L-aspartate, Lhistidine, L-leucine, L-ornithine, L-phenylalanine, L-proline, L-serine, L-tryptophan, 3-hydroxybenzoate, 4-hydroxybenzoate and L-phenylacetate. + , Positive; - , negative; $(+)$, weakly positive.

\begin{tabular}{|c|c|c|c|}
\hline Characteristic & 1 & 2 & 3 \\
\hline \multicolumn{4}{|l|}{ Hydrolysis of: } \\
\hline Aesculin & - & $(+)$ & - \\
\hline$p \mathrm{NP}-\beta$-D-glucuronide & - & + & - \\
\hline$p$ NP- $\beta$-D-xylopyranoside & + & + & - \\
\hline pNP-phenyl-phosphonate & + & - & + \\
\hline 2-Deoxythymidine- $5^{\prime}$ - $p$ NP-phosphate & + & - & - \\
\hline L-Alanine- $p \mathrm{NA}$ & + & - & - \\
\hline L-Proline- $p \mathrm{NA}$ & + & + & - \\
\hline \multicolumn{4}{|l|}{ Assimilation of: } \\
\hline$N$-Acetyl-D-glucosamine & + & + & - \\
\hline L-Arabinose & - & + & + \\
\hline p-Arbutin & - & - & + \\
\hline Maltose & + & + & - \\
\hline$\alpha$-Melibiose & + & - & + \\
\hline L-Rhamnose & - & + & - \\
\hline Salicin & + & - & + \\
\hline D-Xylose & + & - & + \\
\hline i-Inositol & - & + & - \\
\hline Maltitol & + & - & + \\
\hline D-Sorbitol & - & + & - \\
\hline
\end{tabular}


genus belongs to the family 'Cyclobacteriaceae', phylum 'Bacteroidetes'. The type species is Fontibacter flavus.

\section{Description of Fontibacter flavus sp. nov.}

Fontibacter flavus (fla'vus. L. masc. adj. flavus yellow).

The description is as for the genus with the following additional properties. Cells are $1.5-3.0 \mu \mathrm{m}$ in length and $0.3-0.5 \mu \mathrm{m}$ in diameter. Accumulates poly- $\beta$-hydroxybutyrate granules as inclusion bodies. Good growth is seen after $48 \mathrm{~h}$ on nutrient agar and tryptic soy agar at $25-40{ }^{\circ} \mathrm{C}$. No growth occurs at temperatures $<20{ }^{\circ} \mathrm{C}$ and $>45{ }^{\circ} \mathrm{C}$. No growth is observed on MacConkey agar. Growth is observed on nutrient agar containing $1-3 \% \mathrm{NaCl}$, but not at $>4 \%$ $\mathrm{NaCl}$. Colonies on nutrient agar are smooth and circular, orange-pigmented and show regular edges. The following compounds are utilized weakly as sole carbon sources: cellobiose, D-fructose, D-galactose, D-glucose, maltose, D-mannose, melibiose, sucrose and trehalose. NAcetylgalactosamine, gluconate, D-ribose, D-adonitol, Dmannitol, acetate, propionate, cis-aconitate, trans-aconitate, adipate, 4-aminobutyrate, azelate, citrate, fumarate, glutarate, DL-3-hydroxybutyrate, itaconate, DL-lactate, L-malate, mesaconate, oxoglutarate, pyruvate, suberate, L-alanine, $\beta$ alanine, L-aspartate, L-histidine, L-leucine, L-ornithine, Lphenylalanine, L-proline, L-serine, L-tryptophan, 3-hydroxybenzoate, 4-hydroxybenzoate and L-phenylacetate are not utilized. Hydrolyses $o$-nitrophenyl (NP)- $\beta$-D-galactopyranoside, $p \mathrm{NP}-\alpha$-D-glucopyranoside, $p \mathrm{NP}-\beta$-D-glucopyranoside, bis- $p$ NP-phosphate, $p$ NP-phosphoryl-choline and L-glutamate- $\gamma$-3-carboxy- $p$-nitroanilide (NA). The major cellular fatty acids $(>9 \%)$ are iso- $\mathrm{C}_{15: 0}$, iso- $\mathrm{C}_{17: 1} \omega 9 \mathrm{c}$ and iso- $\mathrm{C}_{17: 0}$ $3-\mathrm{OH}$. The polar lipid profile is composed of $\mathrm{PE}$ and unknown polar lipid L2 as the major components, moderate amounts of unknown aminolipid AL1 and five unknown polar lipids (L1, L3, L4, L5, L6), and minor to trace amounts of unknown phospholipid PL1 and two polar lipids (L7, L8).

The type strain is CC-GZM- $130^{\mathrm{T}}\left(=\right.$ CCUG $57694^{\mathrm{T}}=\mathrm{CCM}$ $7650^{\mathrm{T}}$ ), isolated from the Guan-zing-ling hot spring, Taiwan. The DNA G+C content of the type strain is $53.2 \mathrm{~mol} \%$. Detailed fatty acid composition of the type strain is given in Table 1.

\section{Acknowledgements}

This research work was kindly supported by a grant from the National Science Council, Taiwan, ROC. We thank W.-S. Huang, M.-H. Hung and H.-R. Huang for technical assistance and collection of hot spring samples and Dr Jean Euzéby for his advice on nomenclature.

\section{References}

Altenburger, P., Kämpfer, P., Makristathis, A., Lubitz, W. \& Busse, H.-J. (1996). Classification of bacteria isolated from a medieval wall painting. J Biotechnol 47, 39-52.

Brettar, I., Christen, R. \& Höfle, M. G. (2004a). Belliella baltica gen. nov., sp. nov., a novel marine bacterium of the Cytophaga-
Flavobacterium-Bacteroides group isolated from surface water of the central Baltic Sea. Int J Syst Evol Microbiol 54, 65-70.

Brettar, I., Christen, R. \& Höfle, M. G. (2004b). Aquiflexum balticum gen. nov., sp. nov., a novel marine bacterium of the CytophagaFlavobacterium-Bacteroides group isolated from surface water of the central Baltic Sea. Int J Syst Evol Microbiol 54, 2335-2341.

Busse, H.-J. \& Auling, G. (1988). Polyamine pattern as a chemotaxonomic marker within the Proteobacteria. Syst Appl Microbiol 11, 1-8.

Chung, Y. C., Kobayashi, T., Kanai, H., Akiba, T. \& Kudo, T. (1995). Purification and properties of extracellular amylase from the hyperthermophilic archeon Thermococcus profundus DT5432. Appl Environ Microbiol 61, 1502-1506.

Collins, M. D. (1985). Analysis of isoprenoid quinones. Methods Microbiol 18, 329-366.

Gerhardt, P., Murray, R. G. E., Wood, W. A. \& Krieg, N. R. (editors) (1994). Methods for General and Molecular Bacteriology. Washington, DC: American Society for Microbiology.

Kämpfer, P. \& Kroppenstedt, R. M. (1996). Numerical analysis of fatty acid patterns of coryneform bacteria and related taxa. Can J Microbiol 42, 989-1005.

Kämpfer, P., Steiof, M. \& Dott, W. (1991). Microbiological characterization of a fuel-oil contaminated site including numerical identification of heterotrophic water and soil bacteria. Microb Ecol 21, 227-251.

Kämpfer, P., Dreyer, U., Neef, A., Dott, W. \& Busse, H.-J. (2003). Chryseobacterium defluvii sp. nov., isolated from wastewater. Int J Syst Evol Microbiol 53, 93-97.

Ludwig, W., Strunk, O., Westram, R., Richter, L., Meier, H., Yadhukumar, Buchner, A., Lai, T., Steppi, S. \& other authors (2004). ARB: a software environment for sequence data. Nucleic Acids Res 32, 1363-1371.

Ludwig, W., Euzéby, J. \& Whitman, W. B. (2008). Draft taxonomic outline of the Bacteroidetes, Planctomycetes, Chlamydiae, Spirochaetes, Fibrobacteres, Fusobacteria, Acidobacteria, Verrucomicrobia, Dictyoglomi and Gemmatimonadetes for Volume 4 of the second edition of Bergey's Manual of Systematic Bacteriology. http://www. bergeys.org/outlines/Bergeys_Vol_4_Outline.pdf

Minnikin, D. E., O’Donnell, A. G., Goodfellow, M., Alderson, G., Athalye, M., Schaal, A. \& Parlett, J. H. (1984). An integrated procedure for the extraction of bacterial isoprenoid quinones and polar lipids. J Microbiol Methods 2, 233-241.

Olsen, G. J., Matsuda, H., Hagstrom, R. \& Overbeek, R. (1994). fastDNAml: a tool for construction of phylogenetic trees of DNA sequences using maximum likelihood. Comput Appl Biosci 10, 41-48.

Pruesse, E., Quast, C., Knittel, K., Fuchs, B. M., Ludwig, W., Peplies, J. \& Glöckner, F. O. (2007). SILVA: a comprehensive online resource for quality checked and aligned ribosomal RNA sequence data compatible with ARB. Nucleic Acids Res 35, 7188-7196.

Stolz, A., Busse, H.-J. \& Kämpfer, P. (2007). Pseudomonas knackmussii sp. nov. Int J Syst Evol Microbiol 57, 572-576.

Strunk, O., Gross, O., Reichel, B. \& other authors (2000). ARB: a software environment for sequence data. Department of Microbiology, Technische Universität München, Munich, Germany. http:// www.arb-home.de

Tindall, B. J. (1990a). A comparative study of the lipid composition of Halobacterium saccharovorum from various sources. Syst Appl Microbiol 13, 128-130.

Tindall, B. J. (1990b). Lipid composition of Halobacterium lacusprofundi. FEMS Microbiol Lett 66, 199-202.

Young, C.-C., Lin, S.-Y., Arun, A. B., Shen, F.-T., Chen, W.-M., Rekha, P. D., Langer, S., Busse, H.-J. \& Kämpfer, P. (2009). Algoriphagus olei sp. nov., isolated from oil-contaminated soil. Int J Syst Evol Microbiol 59, 2909-2915. 